\title{
Anti-Inflammatory Effects of Concentrated Ethanol Extracts of Edelweiss (Leontopodium alpinum Cass.) Callus Cultures towards Human Keratinocytes and Endothelial Cells
}

\author{
Lulli Daniela, ${ }^{1}$ Potapovich Alla, ${ }^{1,2}$ Riccardo Maurelli, ${ }^{1}$ Dellambra Elena, ${ }^{1}$ \\ Pressi Giovanna, ${ }^{3}$ Kostyuk Vladimir, ${ }^{1,2}$ Dal Toso Roberto, ${ }^{3}$ De Luca Chiara, ${ }^{1}$ \\ Pastore Saveria, ${ }^{1}$ and Korkina Liudmila ${ }^{1}$ \\ ${ }^{1}$ Laboratory of Tissue Engineering and Skin Pathophysiology, Dermatology Institute (IDI IRCCS), Via Monti di Creta 104, \\ 00167 Rome, Italy \\ ${ }^{2}$ Biology Department, Belarus State University, Nezavisimosti Avenue 4, 220050 Minsk, Belarus \\ ${ }^{3}$ Institute of Biotechnology Research (I.R.B. S.r.l.), Via Lago di Tovel 7, 36077 Altavilla Vicentina, Italy
}

Correspondence should be addressed to Korkina Liudmila, 1.korkina@idi.it

Received 9 May 2012; Revised 30 July 2012; Accepted 31 July 2012

Academic Editor: Peter Plomgaard

Copyright (C) 2012 Lulli Daniela et al. This is an open access article distributed under the Creative Commons Attribution License, which permits unrestricted use, distribution, and reproduction in any medium, provided the original work is properly cited.

\begin{abstract}
Edelweiss (Leontopodium alpinum Cass.) is traditionally employed in folk medicine as an anti-inflammatory remedy. In nature, the plant is sparsely available and protected; therefore production of callus cultures was established. A concentrated ethanolic extract of culture homogenate, with leontopodic acid representing $55 \pm 2 \%$ of the total phenolic fraction (ECC55), was characterized for antiinflammatory properties in primary human keratinocytes (PHKs) and endotheliocytes (HUVECs). Inflammatory responses were induced by UVA+UVB, lipopolysaccharide (LPS), oxidized low-density lipoprotein (oxLDL), and a mixture of proinflammatory cytokines. Trichostatin A, a sirtuin inhibitor, was used to induce keratinocyte inflammatory senescence. ECC55 (10-50 $\mu \mathrm{g} / \mathrm{mL})$ protected PHK from solar UV-driven damage, by enhancing early intracellular levels of nitric oxide, although not affecting UVinduced expression of inflammatory genes. Comparison of the dose-dependent inhibition of chemokine (IL-8, IP-10, MCP-1) and growth factor (GM-CSF) release from PHK activated by TNF $\alpha$ + IFN $\gamma$ showed that leontopodic acid was mainly responsible for the inhibitory effects of ECC55. Sirtuin-inhibited cell cycle, proliferation, and apoptosis markers were restored by ECC55. The extract inhibited LPS-induced IL-6 and VCAM1 genes in HUVEC, as well as oxLDL-induced selective VCAM1 overexpression. Conclusion. Edelweiss cell cultures could be a valuable source of anti-inflammatory substances potentially applicable for chronic inflammatory skin diseases and bacterial and atherogenic inflammation.
\end{abstract}

\section{Introduction}

Since ancient time, plants have been undiminished sources of products traditionally used for medicinal and skin care purposes. In our highly technological era, natural substances of plant origin remain major active principles of numerous drugs and "ceuticals" (nutraceuticals and cosmeceuticals). According to pharmacological statistics, 12 out of 40 antiinflammatory drugs approved between 1983 and 1994 worldwide were derived from or based on secondary plant metabolites, mainly polyphenols [1]. Recently, a number of in vitro and in vivo animal studies have provided first scientific evidence for ethnopharmacological use of Leontopodium alpinum Cass. (family Asteraceae, named also Edelweiss) as a potent anti-inflammatory [2-5] and antibacterial remedy $[6,7]$. Edelweiss is a famous plant sparsely distributed in high mountains of Europe and Asia at altitude of 1800 $3000 \mathrm{~m}$. The rare plant spontaneously grows in inaccessible areas, and it is protected in many countries [8]. In European folk medicine, aerial parts (leaves, flowers, and stems) of Edelweiss have been used to attenuate inflammation and pain in respiratory system (tonsillitis, bronchitis, and pneulmonitis), gastrointestinal system (gastritis and colitis) [8], joints (rheumatoid arthritis) [9], and tumor-affected tissues (skin and connective tissues over breast cancer) [10]. In laboratory experiments, extracts of dried roots of Edelweiss possessed 
anti-inflammatory properties $[2,5]$. During the last few years, anti-inflammatory properties of Edelweiss have been extensively exploited in cosmetic preparations in order to possibly protect the skin against solar irradiation-induced chronic skin inflammation, eventually leading to premature aging and high incidence of skin tumors [10].

The great majority of health properties of this plant have been attributed to the presence and the spectrum of polyphenolic secondary metabolites. Edelweiss contains a wide variety of polyphenols belonging to classes of phenylpropanoids (phenolic acids, glycosides, flavonoids, coumarines, and lignans), terpenes (sesquiterpenes and diterpene acids), and alkaloids (benzofuran and pyrane derivatives) [11]. The ethnopharmacological use of Edelweiss is supported by the isolation of a number of phenylpropanoids possessing antiinflammatory and antibacterial properties from the plant root, its aerial parts, or from hairy root cultures [2]. The analytical assessment of extracts of aerial parts of Edelweiss revealed glycosides and aglycones of flavonoids (luteolin, quercetin, and apigenin) as well as high content of leontopodic, chlorogenic, and 3, 5-dicaffeoylquinic acids [12]. By chemical structure, leontopodic acids (isomers A and B, LA1, and LA2, resp.) contain four phenylpropanoid moieties connected to a backbone of glucaric acid. Later publications described LA1 and LA2 as having the greatest impact on beneficial biological effects of Edelweiss herb extracts $[6,11]$. The extracts also display antioxidant, DNA-protecting, and analgesic effects, proven in different in vivo models [5].

Taking into account growing public concern about overexploitation of rare plant species for medicinal and cosmetic use, plantations of cultivated Edelweiss were established in Switzerland [10]. Recent advances in molecular biology and biochemistry of secondary plant metabolites, metabolic bioengineering, and scaleup production of desired molecules in stable plant cell/tissue cultures seem to open a new era for classical ethnopharmacologically relevant plants [13]. Early studies of aseptic plant cultures in vitro reviewed by Thorpe [14] led to the development of hairy root, embryo, and callus/tissue cultures. Plant cell/tissue cultures subjected to proper eliciting seem to be an ideal "chemical factory" for the biotechnological production of secondary metabolites providing controlled, uncontaminated, and allyear-round biosynthesis of complex molecules. Moreover, plant polyphenols synthesized in plant cell cultures are not subjected to polymerization process, which usually takes place in plants to construct cell walls and to close wounds [15]. Hence, the yield of monomeric polyphenolic molecules could be much higher in cultures than in mature plant parts, and their extraction and purification are greatly simplified.

In the present work, mechanisms of anti-inflammatory activity of concentrated ethanol extracts of Leontopodium alpinum callus cultures, containing phenolic fraction with $55 \%$ of LA1 and LA2, were evaluated in two in vitro models of primary human keratinocytes and endothelial cells activated by physiologically relevant proinflammatory stimuli, such as solar UV irradiation, bacterial lipopolysaccharide (LPS), oxidized low-density lipoprotein (oxLDL), mixture of proinflammatory cytokines (tumor necrosis factor alpha + interferon gamma), and sirtuin inhibitor (trichostatin A).
Comparison with commercially available pure LA showed a prominent anti-inflammatory action of the extract exerted through several distinct molecular pathways that largely depended on the presence of LAs.

\section{Materials and Methods}

2.1. Solvents and Reagents. All solvents and reagents were of the highest purity available from Sigma Aldrich, Milan, Italy, if not indicated otherwise. As reference plant polyphenols, commercial LA, quercetin $(\mathrm{Qr})$, and resveratrol $(\mathrm{Rv})$ were used.

2.2. Plant Cell Cultures. In order to protect rare species of Edelweiss from extinguishing and facilitate synthesis and extraction of biologically active substances, stable callus cultures derived from Leontopodium alpinum seeds were established. The growth and specific eliciting conditions allowed achieving a higher yield of LAs and chlorogenic acids compared with extracts from the mature plant parts.

Cell cultures of Leontopodium alpinum (Edelweiss, ECC) were obtained from commercially available seeds. The seeds were first sterilized and then laid on a Petri dish until small sterile plantlets were grown. Then, explants were collected and transferred to a new solid agar plate with Gamborg B5 medium (Sigma Aldrich, Milan, Italy) containing $20 \mathrm{~g} / \mathrm{L}$ sucrose, $1 \mathrm{~g} / \mathrm{L}$ plant peptone, $1 \mathrm{mg} / \mathrm{L}$ kinetin, $1 \mathrm{mg} / \mathrm{L}$ naphthalene acetic acid, and $0.2 \mathrm{mg} / \mathrm{L}$ indol acetic acid at $\mathrm{pH}$ 6.5. Calli grown on solid Gamborg B5 medium were subjected to subculture for at least 3 months and subsequently were used to inoculate Erlenmeyer flasks of $1 \mathrm{~L}$ volume, with the final liquid Gamborg B5 medium content of $250 \mathrm{~mL}$ for each flask. After 14 days of fermentation at $25^{\circ} \mathrm{C}$ in the dark, the cells were collected, and the secondary metabolites were extracted.

2.3. Plan Cell Extract Preparation and Analysis. Fifteen-dayold cell cultures (total volume $15 \mathrm{~L}$ ) were filtered, and the medium was discarded. After addition of $15 \mathrm{~g}$ of solid ascorbic acid, cells were extracted with two volumes of ethanol, homogenized, centrifuged, and concentrated under reduced pressure (ECC). The phenolic compounds present in the aqueous residue were quantitatively recovered by solid-phase extraction using a column $(7 \times 50 \mathrm{~cm})$ containing $1.5 \mathrm{~kg}$ of XAD-4 resin suspended in 5\% aqueous $\mathrm{HCOOH}$. The column was washed with $\mathrm{H}_{2} \mathrm{O}$ and eluted with $80 \%$ ethanol. Fractions containing caffeic derivatives were concentrated under reduced pressure, and the aqueous residue freeze dried, yielding $14 \mathrm{~g}$ of grey powder.

The detailed analysis of the callus cultures extract was performed by HPLC-ESI-MS using an HPL chromatograph (System Gold 127, Beckman Coulter) connected to a massspectrometer (Esquire 6000) equipped with an electrospray ionization and ion-trapping system (ESI, Bruker Daltonics). All analyses were repeated twice. All reagents and reference molecules of phenolics used were of analytical grade (Sigma Aldrich, Milan, Italy), and HPLC solvents were of gradient grade. 
In order to separate the different caffeic acid derivatives, the powder was resuspended in $\mathrm{H}_{2} \mathrm{O}$ and completely dissolved with a few drops of concentrated $\mathrm{NH}_{4} \mathrm{OH}$. Solution was submitted to Sephadex LH20 CC $(8 \times 24 \mathrm{~cm})$ suspended in aqueous $15 \%$ ethanol containing $1 \% \mathrm{HCOOH}$. The column was first eluted with the same solvent, and fractions $(100 \mathrm{~mL}$ each) were collected and analyzed by HPLC. Fractions $44-52$ were pooled and lyophilized yielding $2.75 \mathrm{~g}$ of pure chlorogenic acid. Elution was continued with aqueous $30 \%$ ethanol $+1 \% \mathrm{HCOOH}$, and fractions $75-$ 93 gave $6.53 \mathrm{~g}$ of an LA1 and LA2 mixture. In order to separate leontopodic acids, freeze-dried fractions 75-93 were submitted to a second chromatography in reverse phase on RP-C18 LiChrosphere (Merck, Darmstadt, Germany). A column $(\mathrm{cm} 5 \times 40)$, filled with resin suspended in aqueous $\mathrm{CH}_{3} \mathrm{CN} 1 \%$ added with $\mathrm{HCOOH} 1 \%$, was used. The column was eluted with increasing amounts of $\mathrm{CH}_{3} \mathrm{CN}$ added of $1 \% \mathrm{HCOOH}$, and $150 \mathrm{~mL}$ fractions were collected. Pure LA1 and LA2 were recovered in the fractions with $20 \%$ of $\mathrm{CH}_{3} \mathrm{CN}$ and $50 \%$, respectively. In order to separate LA1 and LA2, the powder obtained by freeze drying of fractions 7593 was submitted to a second-column chromatography in reverse phase on RP-C18 LiChrosphere (Merck, Darmstadt, Germany) using a column $(\mathrm{cm} 5 \times 40)$, filled with resin suspended in aqueous $1 \% \mathrm{CH}_{3} \mathrm{CN}+1 \% \mathrm{HCOOH}$. The column was eluted with increasing amounts of $\mathrm{CH}_{3} \mathrm{CN}$ together with $1 \% \mathrm{HCOOH}$, and $150 \mathrm{~mL}$ fractions were collected [16]. The material (ECC55), which was used in biological experiments, was finally analysed by HPLC-ESIMS method.

\subsection{Human Cell Cultures}

2.4.1. Primary Human Keratinocytes (PHKs). PHKs obtained from skin biopsies of healthy subjects $(n=5)$ [17] were seeded onto $9.6 \mathrm{~cm}^{2}$ wells $(60,000$ cells/well $)$ and cultured in a $5 \% \quad \mathrm{CO}_{2}$ humidified atmosphere in keratinocyte growth medium: DMEM and Ham's F12 (both from Lonza, Visp, Switzerland) media (2:1 mixture) containing $10 \%$ fetal bovine serum (Invitrogen, USA), $0.18 \mathrm{mM}$ adenine, $0.4 \mu \mathrm{g} / \mathrm{mL}$ hydrocortisone (both from Calbiochem, USA), $5 \mu \mathrm{g} / \mathrm{mL}$ insulin, $0.1 \mathrm{nM}$ cholera toxin, $2 \mathrm{nM}$ triiodothyronine, $50 \mathrm{IU}$ to $50 \mu \mathrm{g} / \mathrm{mL}$ penicillin-streptomycin, $4 \mathrm{mM}$ glutamine, and $10 \mathrm{ng} / \mathrm{mL}$ epidermal growth factor (Austral Biologicals, USA). The protocol of the study was approved by the local Ethical Committee (IDI IRCCS-San Carlo Hospital), and informed consent for skin biopsy was signed by all the participants.

2.4.2. Human Endothelial Cells. Human umbilical vein endothelial cells (HUVECs) were purchased from Lonza (Verviers, Belgium) and were cultured in endothelial cell growth medium (EGM-2 BulletKit, Lonza, Verviers, Belgium) and supplemented with $2 \%$ fetal bovine serum (FBS), at $37^{\circ} \mathrm{C}$ in humidified atmosphere containing $5 \% \mathrm{CO}_{2}$. All experiments were performed with HUVEC cells at the fourth to seventh passage.
2.5. Induction of Inflammatory Responses. Inflammatory response to low-dose UVA+UVB irradiation $(30 \mathrm{~s}$, UVA $1.0 \mathrm{~J} / \mathrm{cm}^{2}+\mathrm{UVB} 0.1 \mathrm{~J} / \mathrm{cm}^{2}$ ) produced by solar simulator (Dermalight Vario with filter A2, Dr. Hoehnle AG, UV Technology, Planegg, Germany) with emission spectrum from $280 \mathrm{~nm}$ and emission peak at $375 \mathrm{~nm}$ was evaluated. The light effluence rate on the cell monolayer was $40 \mathrm{~mW} / \mathrm{cm}^{2}$. ECC55 $(25 \mu \mathrm{g} / \mathrm{mL})$ or reference plant polyphenols $(25 \mu \mathrm{g} / \mathrm{mL})$ or corresponding vehicle was added $30 \mathrm{~min}$ before UV exposure [18].

Two days after seeding, PHKs were treated with different doses ( 1 to $100 \mu \mathrm{g} / \mathrm{mL}$ ) of ECC extracts for 48 hours. Then, $100 \mathrm{nM}$ Trichostatin A (TSA) was added, and $24 \mathrm{~h}$ later the medium was changed for starvation medium: DMEM, glutamine $(4 \mathrm{mM})$, and penicillin-streptomycin (50 IU and $50 \mu \mathrm{g} / \mathrm{mL}$, resp.). PHKs were cultivated for $24 \mathrm{~h}$ and then collected and used for further analysis.

PHKs were preincubated with escalating concentration of either ECC55 or commercial LA (from 1 to $100 \mu \mathrm{g} / \mathrm{mL}$ ) for $1 \mathrm{~h}$. Then, $100 \mathrm{ng} / \mathrm{mL}$ of tumor necrosis factor alpha $(\mathrm{TNF} \alpha)$ and $100 \mathrm{U} / \mathrm{mL}$ interferon gamma (IFN $\gamma$ ) were added. The combination of two proinflammatory factors induced maximal expression and release of cytokines and chemokines from PHK [19]. After $24 \mathrm{~h}$, concentrations of interleukin 8 (IL-8), interferon gamma-produced protein of $10 \mathrm{kDa}$ (IP-10), granulocyte macrophage colony-stimulating factor (GM-CSF), and monocyte chemotactic protein 1 (MCP-1) were measured by enzyme-linked immunosorbent assay (ELISA).

HUVEC cells were treated with LPS (055:B5 SigmaAldrich, $1 \mu \mathrm{g} / \mathrm{mL}$ ) or vehicle (water) in the presence or absence of ECC55 or reference plant polyphenols $(25 \mu \mathrm{g} / \mathrm{mL})$ for $3-4 \mathrm{~h}$. Then, cells were scraped, and the whole cell homogenates were prepared for further extraction of RNA as described below.

Oxidised low-density lipoproteins (oxLDLs) were prepared as described previously [20]. In brief, human native LDL was diluted to a $200 \mu \mathrm{g}$ protein $/ \mathrm{mL}$ in phosphatebuffered saline ( $\mathrm{pH}$ 7.4) and incubated with $15 \mu \mathrm{g} / \mathrm{mL}$ human myeloperoxidase (Calbiochem, San Diego, CA, USA), $50 \mu \mathrm{M}$ nitrite, and $0.6 \mathrm{mM}$ hydrogen peroxide at $37^{\circ} \mathrm{C}$ for $30 \mathrm{~min}$. To stop the reaction and to remove the excess of hydrogen peroxide, $0.1 \mathrm{mg} / \mathrm{mL}$ of catalase was added. Lipid peroxides were measured using ProxiDetect Kit from Sigma Aldrich (Milan, Italy). Their content in oxLDL ranged from 190 to $210 \mathrm{~mol} / \mathrm{mol} \mathrm{LDL}$. In the in vitro experiments, $10 \mu \mathrm{g}$ protein $/ \mathrm{mL}$ oxLDL dissolved in DMSO was added to HUVEC cultures. Cells were incubated with oxLDL in the presence or absence of ECC55 for $1 \mathrm{~h}$ or $4 \mathrm{~h}$. The control cultures were incubated with vehicles for ECC55 (ethanol) and/or oxLDL (DMSO) added at the same concentrations $(0.2 \% \mathrm{v} / \mathrm{v})$ as in the experimental cultures.

\subsection{Assessment of Inflammatory Responses}

2.6.1. Total RNA Isolation and RT-PCR. Total RNA was isolated from frozen HUVEC and PHK using the GenElute Mammalian Total RNA Kit in accordance with manufacturer's instructions. Total RNA $(3 \mu \mathrm{g})$ was reverse 
transcribed using the iScript cDNA Synthesis Kit at $25^{\circ} \mathrm{C}$ for $5 \mathrm{~min}$ and $42^{\circ} \mathrm{C}$ for $30 \mathrm{~min}$, followed by $85^{\circ} \mathrm{C}$ for $5 \mathrm{~min}$ in a final reaction volume of $60 \mu \mathrm{l}$. cDNA was amplified with IQ SYBR green Supermix using the MiniOpticon realtime PCR detection system (all reagents were from BioRad, Hercules, USA). Melt curve analysis was performed to confirm the specificity of the amplified products. Signal of housekeeping gene beta-actin was used as the reference. Changes were calculated with the comparative $\mathrm{Ct}$ method ( $\Delta \Delta \mathrm{Ct}$ ) according to [21]. Total RNA from each experimental point was reverse-transcribed in duplicate, and all PCR amplifications were repeated two times. The following primer sets were designed using Primer-BLAST (NCBI) and were synthesized by Eurofins MWG Operon (Ebersberg, Germany): $\beta$-actin fwd: 5'-AATCTGGCACCACACCTTCTAC-3'; $\beta$-actin rev: $5^{\prime}$-ATAGCACAGCCTGGATAGCAAC$3^{\prime}$; 18S rRNA fwd: 5'-TCCCCCAACTTCTTAGAGG-3'; 18S rRNA rev: 5'-GCTTATGACCCGCACTTAC-3'; iOS fwd: 5' $5^{\prime}$ TACTCCACCAACAATGGCAA-3'; iOS rev: $5^{\prime}$ ATAGCGGATGAGCTGAGCAT-3' ; IL-6 fwd: 5' -GTGTGAAAGCAGCAAAGAG-3'; IL-6rev: $5^{\prime}$-CTCCAAAAGACCAGTGATG-3'; TNF- $\alpha$ fwd: 5' ${ }^{\prime}$-TCCTTCAGACACCCTCAACC-3' ; TNF- $\alpha$ rev: $5^{\prime}$-AGGCCCCAGTTTGAATTCTT3'; IL- $1 \alpha$ fwd: 5'-TGGCTCATTTTCCCTCAAAAGTTG$3^{\prime}$; IL- $1 \alpha$ rev: $5^{\prime}$-AGAAATCGTGAAATCCGAAGTCAAG-3'; COX-2 frw: 5'-TTCTCCTTGAAAGGACTTATGGGTAA3'; COX-2 rev: 5'-AGAACTTGCATTGATGGTGACTGTTT-3'; SOD-2 frw: 5'-GGCCTACGTGAACAACCTGAA3'; SOD-2 rev: 5' -CTGTAACATCTCCCTTGGCCA-3' MCP 1frw: 5'-AAGCAGAAGTGGGTTCAGGA-3'; MCP1 rev: 5' -TAAAACAGGGTGTCTGGGGA-3'; MMP 1frw: 5' TGTGGACCATGCCATTGAGA-3'; MMP 1rev: 5'-TCTGCTTGACCCTCAGAGACC-3'; MMP 9frw: 5' -GGAGACCTGAGAACCAATC-3'; MMP9 rev: 5'-CACCCGAGTGTAACCATAG-3'; IL-8 frw: 5'-GTCCTTGTTCCACTGTGCCT-3'; IL-8 rev: 5'-GCTTCCACATGTCCTCACAA3'; ICAM 1frw: 5' -CCCATGAAACCGAACACAC-3'; ICAM 1rev: 5' -ACTCTGTTCAGTGTGGCACC-3'; VCAM fwr: 5' TCTCATTGACTTGCAGCACC-3'; VCAM rev: $5^{\prime}$-CTCATTCGTCACCTTCCCAT-3'; IFN $\gamma$ frw: $5^{\prime}$-GCGAAAAAGGAGTCAGATGC-3'; IFN $\gamma$ rev: $5^{\prime}$-CAGGACAACCATTACTGGGA-3'; IP-10 frw: 5'-GGGAGCAAAATCGATGCAGTGCT-3'; IP-10 rev: 5'-GCAGCCTCTGTGTGGTCCATCC-3'; NOX1 frw: 5' -TTAACAGCACGCTGATCCTG3'; NOX1 rev: 5'-TGTGGAAGGTGAGGTTGTGA-3'.

Both $\beta$-actin and $18 \mathrm{~S}$ rRNA were used as housekeeping genes and served for normalization of all the other genes expression.

2.6.2. ELISA for Cytokine Expression. The levels of IL-8, IP10, GM-CSF, and MCP-1 in the conditioned medium of PHK stimulated by the mixture of TNF $\alpha$ and IFN $\gamma$ were measured after $24 \mathrm{~h}$ by using OptELA enzyme-linked immunosorbent assay kits from R\&D, USA, as previously described [17].

2.6.3. Protein Extraction and Western Blotting. For immunoblots, PHKs were extracted on ice by lysis with radio immunoprecipitation assay (RIPA) buffer. Equal amounts of samples $(50 \mu \mathrm{g})$ were subjected to electrophoresis on $12.5 \%$ SDS-polyacrylamide gels and transferred to polyvinylidene difluoride (PVDF) filters (Immobilon-P; Millipore). Filters were soaked in 5\% nonfat dry milk/TBS $(20 \mathrm{mM}$ Tris- $\mathrm{HCl}$, $\mathrm{pH} 7.5$, and $500 \mathrm{mM} \mathrm{NaCl}$ ) at $4{ }^{\circ} \mathrm{C}$ overnight. Western blot was performed using the following monoclonal or polyclonal antibodies: anti-p16 ${ }^{\mathrm{INK} 4 \mathrm{a}}$, anti-p53, anti-p63, anti-PCNA, anti-GAPDH (all from Santa Cruz Biotechnology, Inc., CA, USA), anti-p14 ${ }^{\text {ARF }}$ from Oncogene (Cambridge, MA, USA), and anti-p21 Waf1 (a kind gift from Kristian Helin, University of Copenhagen, Denmark). Filters were incubated for $2 \mathrm{~h}$ at room temperature, washed three times with a solution containing $20 \mathrm{mM}$ Tris- $\mathrm{HCl}, \mathrm{pH} 7.5,500 \mathrm{mM} \mathrm{NaCl}$, and $0.05 \%$ Tween-20, and finally incubated for $1 \mathrm{~h}$ with sheep anti-mouse horse radish peroxidase-labeled immunoglobulin diluted at $1: 5000$ (GE Healthcare, UK).

2.6.4. Assay for Intracellular NO Levels. PHKs were grown to subconfluence in 24-well culture plates, and intracellular NO was detected using 4, 5-diaminofluorescein diacetate (DAF2DA) [22]. In brief, cells were loaded with $2.5 \mu \mathrm{M}$ DAF2DA for $60 \mathrm{~min}$ at $37^{\circ} \mathrm{C}$. After staining, keratinocytes were washed and fixed by $2 \%$ paraformaldehyde for microscopic examination. To quantify the data, cells were detached from culture plates, and the fluorescence of suspended cells was measured on a Shimadzu RF-5301 spectrofluorimeter $\left(\lambda_{\mathrm{ex}}=\right.$ $488 \mathrm{~nm}$ and $\left.\lambda_{\mathrm{fl}}=530 \mathrm{~nm}\right)$.

2.6.5. Assessment of Cell Growth Rate, Vitality, and Membrane Integrity. Effects of proinflammatory stimuli and their combination with ECC55 or reference plant polyphenols on keratinocyte growth and viability as well as membrane integrity were assessed after $24 \mathrm{~h}$ by standard assays. To evaluate the keratinocyte proliferation, subconfluent cultures were trypsinized, and cells were counted under microscope. Cell survival was determined by (3-4, 5-dimethylthiazol-2yl]diphenyl tetrazolium bromide (MTT) colorimetric assay as previously described [23]. Results are the mean values of 12 independent measurements.

2.7. Statistics. Statistical evaluation was carried out with the corresponding software package for Windows XP. The results of all experiments are expressed as the mean values \pm S.D. To assess the difference between experimental groups, Student's $t$-test for unpaired data was applied, and differences were considered to be significant at $P<0.05$.

\section{Results and Discussion}

3.1. Analysis of Leontopodium alpinum Callus Cell Cultures and Their Extract Enriched in Leontopodic Acids (ECC55). Results of HPLS-MS-ESI analysis of ethanolic extracts of callus cell cultures are present in Table 1. They are confronted with the previously published analytical determinations of similar fractions of aerial parts of Edelweiss plant [12]. It could be noticed that, unlikely plant parts, ECC does not contain flavonoids such as isoquercetin, luteolin, apigenin, and their glycosylated derivatives. However, it does contain 
TABle 1: Quantification of phenolic extracts of aerial parts of Edelweiss plant, Leontopodium alpinum callus cultures, and concentrated extract enriched in leontopodic acids (ECC55).

\begin{tabular}{lccc}
\hline Phenolics & Capitula of Edelweiss*(\%) [12] & Leontopodium alpinum callus cultures (\%) & ECC55 (\%) \\
\hline Chlorogenic acid & 0.5 & 1.2 & 24 \\
3,5-Dicaffeoylquinic acid & 1.0 & 0.8 & 21 \\
Leontopodic acid B & 0.5 & 1.0 & 14 \\
Leontopodic acid & 3.0 & 2.2 \\
Luteoline & Traces & - \\
Apigenine & Traces & - \\
Isoquercetin & Traces & - \\
Luteolin-7,4'-di-O- $\beta$-D-glucoside & 0.1 & - \\
Luteolin-4'-O- $\beta$-D-glucoside & 0.3 & - \\
Luteolin-7-O- $\beta$-D-glucoside & Traces & - \\
Luteolin-3'-O- $\beta$-D-glucoside & 0.1 & - \\
Apigenin-7-O- $\beta$-D-glucoside & Traces & - \\
Chrysoeriol-7-O- $\beta$-D-glucoside & Traces & - \\
6-Hydroxy-luteolin-7-O- $\beta$-D-glucoside & & - \\
Pentahydroxyflavone & Traces & 1.5 \\
\hline
\end{tabular}

${ }^{*}$ Content of chlorogenic acid, 3,5-dicaffeoylquinic acid, leontopodic acid B, and leontopodic acid was different in the stems, stem leaves, capitula, inflorescences leaves, and leaves of the basal rosette [12].

approximately $3 \%$ of pentahydroxyflavone used for the plant culture growth. The concentrated extract used in biological experiments (ECC55) contained $41 \%$ of LA1, 24\% of chlorogenic acid, $21 \%$ of 3,5-O-dicaffeoylquinic acid, and $14 \%$ of LA2 (Table 1).

3.2. Extract of Leontopodium alpinum Callus Cell Cultures Enriched in Leontopodic Acids (ECC55) Protects Primary Human Keratinocytes from UVA+UVB-Induced Damage; This Effect Associates to Enhanced Intracellular NO Levels in Irradiated Cells. Preincubation of PHK with $25 \mu \mathrm{g} / \mathrm{mL}$ ECC55 for $30 \mathrm{~min}$ prevented the decrease of cell proliferation observed $1 \mathrm{~h}$ after irradiation with solar simulated UVA+UVB (Figures 1(a)-1(c), and 1(e)). At the same time, intracellular level of NO, significantly increased at $1 \mathrm{~h}$ after irradiation, was further augmented upon exposure to a combination of ECC55 and UVA+UVB (Figure 1(d)). Plant polyphenols have been shown to protect cells against UVA, UVB, or UVC-irradiation-induced cell death or reversible damage although by different mechanisms [23-25]. The protection could be due to the combination of at least three distinct effects: UV absorption, free radical scavenging + metal chelating $=$ antioxidant, and free radical-independent mechanisms of cell death/prosurvival [26]. Higher plants respond to a variety of oxidative stimuli, including enhanced UV irradiation by increasing the biosynthesis of UVA and UVB-absorbing compounds with pronounced antioxidant properties [15]. LA has been shown to possess remarkable antioxidant properties $[5,11]$. An increase in the intracellular levels of NO in UV-exposed keratinocytes occurs by two ways: by the activation of constitutive NO synthases (cNOS) in the early postirradiation period and by the induction of inducible NO synthase (iNOS) at more than $6 \mathrm{~h}$ after irradiation [27]. Our measurements done $1 \mathrm{~h}$ after irradiation also did not reveal any iNOS gene induction by UV (data not shown); however, NO presence in PHK was slight but statistically significantly increased (Figures $1(\mathrm{~b})$ and $1(\mathrm{c})$ ). Usually, NO produced by cNOS is regarded as a protective reaction to UVB irradiation, and low levels of intracellular NO play an essential role of signal transduction to mount adaptive cellular response [28]. The only risk is connected with the possibility of reaction between $\mathrm{NO}$ and superoxide anion-radical $\left(\mathrm{O}_{2}{ }^{-\bullet}\right)$, with the subsequent generation of the cytotoxic peroxynitrite $\mathrm{ONOO}^{-}$[29]. Distinct membranepenetrable plant polyphenols in ECC55, such as LA and chlorogenic acids, might scavenge $\mathrm{O}_{2}^{-\bullet}$, thus inducing a shift of $\mathrm{NO} / \mathrm{ONOO}^{-}$ratio in favor of cytoprotective and redox signaling NO. Collectively, it seems that phenolic extract of Edelweiss callus cultures could provide a novel mode of skin photoprotection enhancing intracellular production of good nitric oxide while decreasing intracellular levels of bad $\mathrm{O}_{2}{ }^{-}$.

3.3. Extract of Leontopodium alpinum Callus Cell Cultures ECC55 Does Not Affect Expression of Inflammatory Genes Induced by UVA+UVB. Keratinocytes appear to be not only primary sensors of exogenous and endogenous stresses, such as toxins, microbes, proinflammatory cytokines, and UV, but also key players of the complex stress-inflammation response in the skin [19]. Exposure to moderate physiological doses of UVA+UVB solar-simulated irradiation resulted in the increased or decreased expression of distinct genes seen already at $1 \mathrm{~h}$ after irradiation and detected for at least $24 \mathrm{~h}$ (Figure 2). Namely, TNF $\alpha$ and IL-6, considered as markers of UV-induced inflammatory response in keratinocytes [18], were significantly and durably induced by UV. The preincubation of PHK with $25 \mu \mathrm{g} / \mathrm{mL}$ of ECC55 did not 


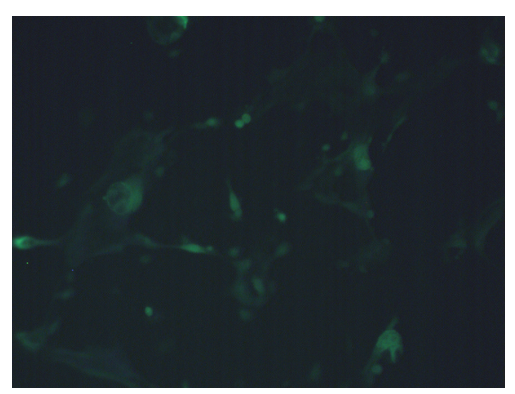

(a)

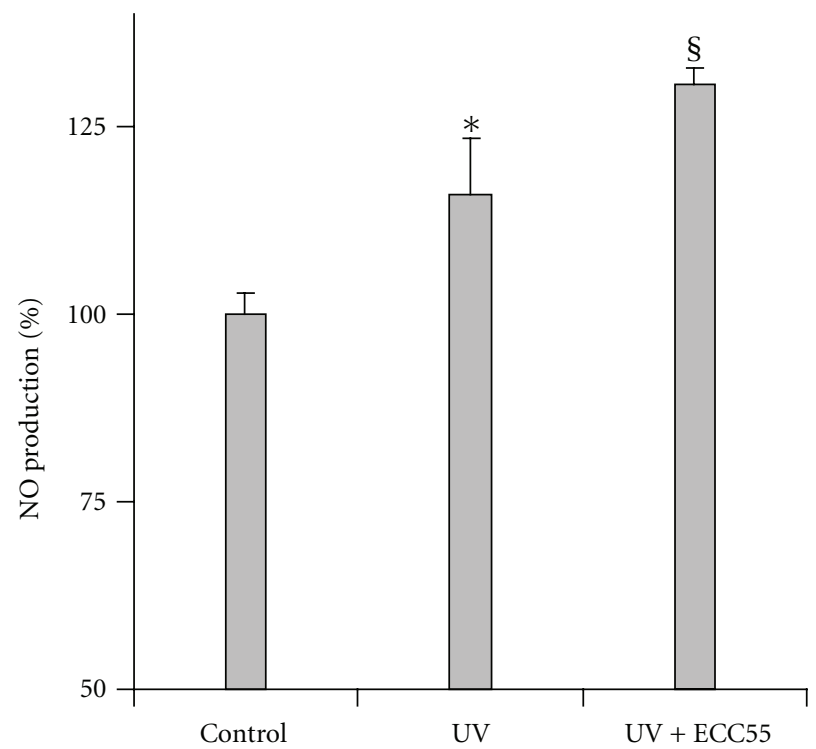

(d)

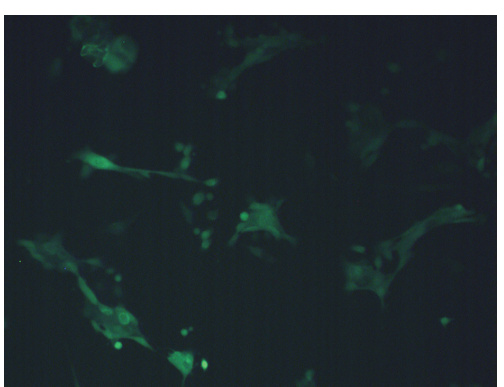

(b)

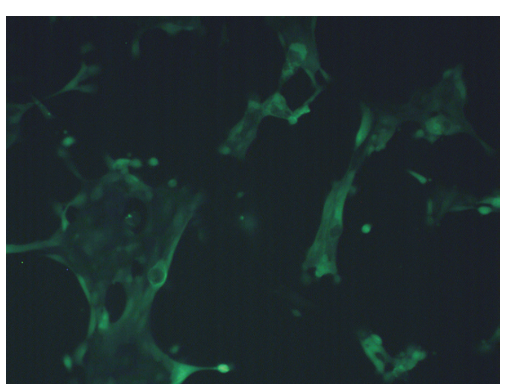

(c)

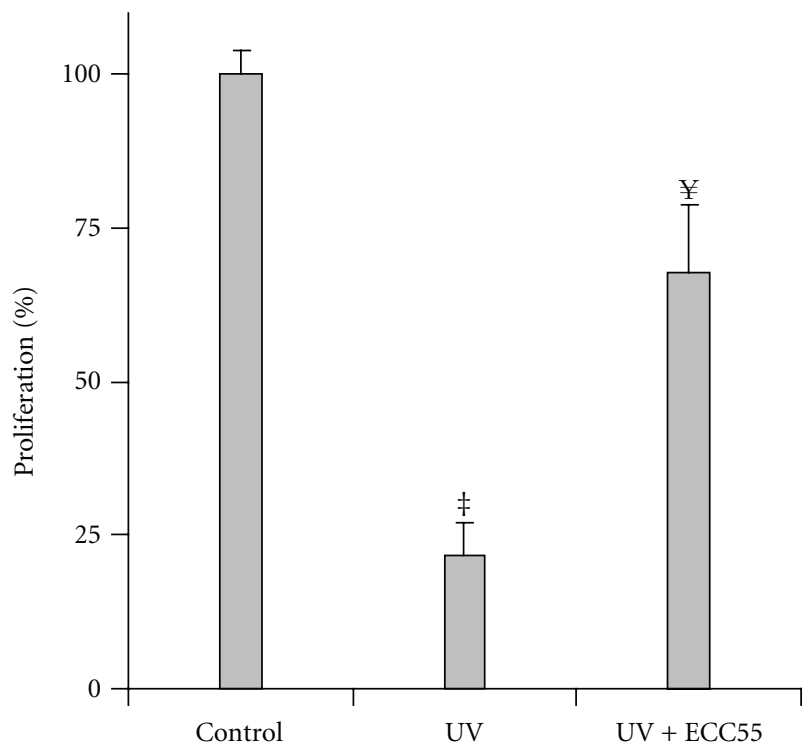

(e)

FIGURE 1: Effects of concentrated ethanol extract of Edelweiss callus cultures (ECC55) on UV-induced keratinocyte damage and intracellular nitric oxide (NO) production. Fluorescent microphotographs of the control untreated keratinocytes (a), keratinocytes $1 \mathrm{~h}$ after irradiation by solar simulating UVA+UVB (b), and keratinocytes pretreated with $25 \mu \mathrm{g} / \mathrm{mL}$ of ECC55 for 30 min and then subjected to UVA+UVB exposure (c). Quantification of intracellular fluorescence of NO-specific fluorescent probe DFA-DA (d). Keratinocyte vitality assessed by MTT test. Error bars in all figures correspond to S.D. ${ }^{*} P<0.05$ versus sham-irradiated control; ${ }^{\S} P<0.05$ versus UV irradiation without ECC55; ${ }^{\ddagger} P<0.01$ versus sham-irradiated control; ${ }^{¥} P<0.01$ versus UV irradiation without ECC55.

affect gene expression. Fast and transient increase of IL1a and COX-2 at $1 \mathrm{~h}$ after irradiation was also insensitive to ECC55. Suppressive and persistent action of solar UV towards the transcripts of two matrix metalloproteinases 1 and 9 (MMP1 and MMP9) was not changed in the presence of ECC55 (Figure 2). Our data suggest that antiinflammatory effects of ECC55 at the transcription level could be cell and stimuli dependent. We concluded that adaptive inflammatory responses of normal keratinocytes to low physiological levels of solar irradiation aiming at protection of cellular vitality and restoration of skin cell functions are not disturbed by the Edelweiss cell extract.

3.4. Extract of Leontopodium alpinum Callus Cell Cultures (ECC55) and Leontopodic Acid Similarly and Dose Dependently Inhibit TNF-Alpha Plus IFN-Gamma-Induced Chemokine (IL-8, MCP-1, and IP-10) and Growth Factor (GM-CSF) Release from Primary Human Keratinocytes. In the course of chronic inflammatory skin disorders, such as psoriasis and atopic dermatitis, epidermal keratinocytes respond to the potent leukocyte-released proinflammatory cytokines tumor necrosis factor (TNF) $\alpha$ and interferon (IFN) $\gamma$ by entering a program of enhanced and durable expression of numerous inflammatory mediators. These keratinocyte-derived chemokines and growth factors attract inflammatory cells (granulocytes and monocytes) to the skin and induce their proliferation, thus maintaining the vicious cycle of chronic skin inflammation [17]. We imitated the situation of chronic skin inflammation by adding the combination of $\mathrm{TNF} \alpha+\mathrm{IFN} \gamma$ (T/I) known to induce maximal expression of proinflammatory chemokines and growth factors, to cultivated human keratinocytes. Of note, background release of IL- 8 was $0.29 \pm 0.04 \mathrm{ng} / 10^{6}$ cells, IP-10 was $0.001 \pm 0.000 \mathrm{ng} / 10^{6}$ cells, GM-CSF was $0.07 \pm$ $0.01 \mathrm{ng} / 10^{6}$ cells, and MCP- 1 was $0.18 \pm 0.02 \mathrm{ng} / 10^{6}$ cells. Spontaneous production of IP-10 and MCP-1 was not 


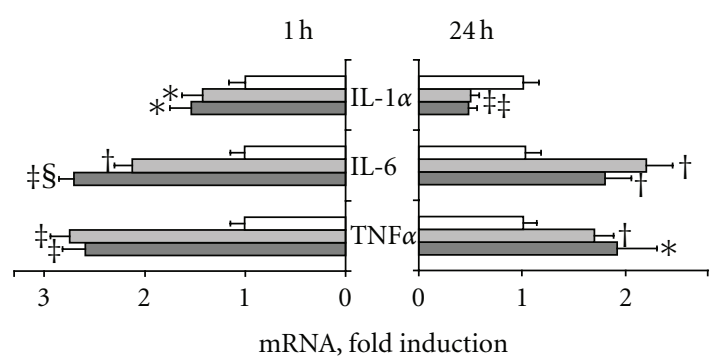

(a)

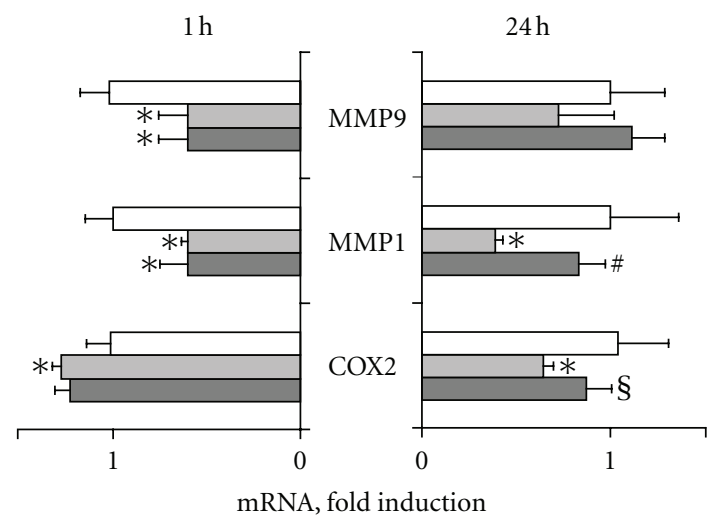

$\square$ Contr
$\square$ UV
$\square$ UV + ECC55

(b)

FIGURE 2: Effects of concentrated ethanol extract of Edelweiss callus cultures (ECC55) on UV-induced gene expression in cultured human keratinocytes. (a) Expression of inflammatory cytokine genes at $1 \mathrm{~h}$ and $24 \mathrm{~h}$ after irradiation with or without preincubation with ECC55 $(25 \mu \mathrm{g} / \mathrm{mL})$. (b) Expression of matrix metalloproteinases 9 and 1 genes (MMP9 and MMP1) as well as cyclooxygenase-2 gene (COX-2) at $1 \mathrm{~h}$ and $24 \mathrm{~h}$ after irradiation. Error bars in all figures correspond to S.D. ${ }^{*} P<0.05 ;{ }^{\dagger} P<0.01 ;{ }^{\ddagger} P<$ 0.001 versus control cells; ${ }^{\S} P<0.05$; ${ }^{\#} P<0.01$ versus $U V$-irradiated cells.

changed in the presence of either ECC55 or pure commercial LA, while basal GM-CSF and IL-8 levels were decreased by ECC55 and LA dose dependently (data not shown). On these grounds, we concluded that the extract and LA affected intrinsic mechanisms of IL-8 and GM-CSF production.

Not surprisingly, T/I strongly activated inflammatory chemokines (IL-8, MCP-1, and IP-10) and growth factor (GM-CSF) release from PHK (Figure 3). Both ECC55 and LA dose dependently inhibited these inflammatory responses. Importantly, LA closely paralleled the activity of equal concentrations of the corticosteroid triamcinolone used as an effective inhibitor of cytokine/chemokine release in PHK and human skin (Figure 3). Concentrations of $50 \%$ inhibition $\left(\mathrm{IC}_{50}\right)$ for GM-CSF were $23 \mu \mathrm{g} / \mathrm{mL}$ for $\mathrm{LA}$ and $50 \mu \mathrm{g} / \mathrm{mL}$ for ECC55, which reflects that exclusively LA could be responsible for the inhibitory action (calculated $\mathrm{IC}_{50}$ for LA within ECC55 is $28 \mu \mathrm{g} / \mathrm{mL}$ ). At the same time, $\mathrm{IC}_{50}$ for IP-10 inhibition was similar $(51 \mu \mathrm{g} / \mathrm{mL}$ and $72 \mu \mathrm{g} / \mathrm{mL}$ for
LA and ECC55, resp.). The same was observed for MCP1 inhibition as well $(51 \mu \mathrm{g} / \mathrm{mL}$ and $66 \mu \mathrm{g} / \mathrm{mL}$ for LA and ECC55, resp.). This allowed us to suggest that other major phenolic constituents of ECC55, such as chlorogenic and/or 3, 5 dicaffeoylquinic acids, could also exert inhibitory effects towards IP-10 and MCP-1 overexpression, as their antiinflammatory activities towards epithelial cells have been reported previously $[30,31]$. Regarding IL-8 inhibition, ECC55 was much less effective than pure LA ( IC $_{50} 9 \mu \mathrm{g} / \mathrm{mL}$ for LA versus $43 \mu \mathrm{g} / \mathrm{mL}$ for ECC55). The low ECC55 inhibitory action could be explained by the possible presence of IL-8-inducing plant polyphenols in the extract. For example, we repeatedly observed de novo synthesis of IL-8 in PHK treated with resveratrol or its glycosylated derivative polydatin $[18,28]$. The identification of IL-8 promoting phenols in the Edelweiss extracts should be performed.

3.5. Extract of Leontopodium alpinum Callus Cell Cultures (ECC55) Reverses Keratinocyte Responses to Trichostatin A: An Inhibitor of Sirtuins. Histone deacetylase inhibitors, such as trichostatin A (TSA), induce a senescence phenotype in cultivated human fibroblasts [32] and in keratinocytes, [33] and Figure 4 (panel b versus panel a). The pretreatment of PHK with ECC55 did not affect normal keratinocyte morphology (Figure 4, panel c versus panel a) and prevented cells from TSA-induced senescence and reduced proliferation (Figure 4, panel d versus panel b). More profound examination of ECC55 effects towards molecular markers, expression of which was affected by TSA [33], showed a dose-dependent decrease of TSA-induced $\mathrm{p} 21^{\text {Waf1 }}$, a cell-cycle regulator of G1 phase (Figure 4, panel e). The expression of the $\mathrm{p} 21^{\mathrm{Waf} 1}$ protein is controlled by the tumor suppressor protein $\mathrm{p} 53$, which mediates the p53-dependent cell cycle arrest in G1 phase in response to stressful conditions [34]. The $\mathrm{p} 21^{\text {Waf1 }}$ protein is cleaved by caspase 3 playing a crucial role in apoptosis following the caspase activation. Accordingly, TSA induced overexpression of both apoptotic markers, p53 and caspase 3 in PHK. Expression of both proteins was significantly reduced by ECC55 before treatment (Figure 4, panels $g$ and h). Moreover, EC55 itself at the concentration of $100 \mu \mathrm{g} / \mathrm{mL}$ inhibited spontaneous p53 expression. In addition to growth arrest, p21 regulates cellular senescence in PHK and interacts with proliferating cell nuclear antigen (PCNA) [33]. Of importance, the proliferative marker PCNA was slightly increased upon action of 5 and $10 \mu \mathrm{g} / \mathrm{mL}$ of ECC 55, although at $100 \mu \mathrm{g} / \mathrm{mL}$, the extract significantly suppressed both spontaneous and TSA-connected PHK proliferation (Figure 4, panel f). On the grounds of these results, we concluded that ECC55 dose dependently opposed Trichostatin A-induced sirtuin-connected cellular events leading to keratinocyte senescence and apoptotic death. Recently, the key role of sirtuin activation in cell/organism aging, apoptosis, and inflammation has been extensively discussed [32, 33, 35, 36]. Pharmacological sirtuin inhibitors, such as Trichostatin A, have been under investigation as targeted apoptosis-inducing anticancer drugs [37]. On contrast, sirtuin activators, such as resveratrol and several other plant-derived polyphenols, have been studied as anti-inflammatory remedies, first of all 

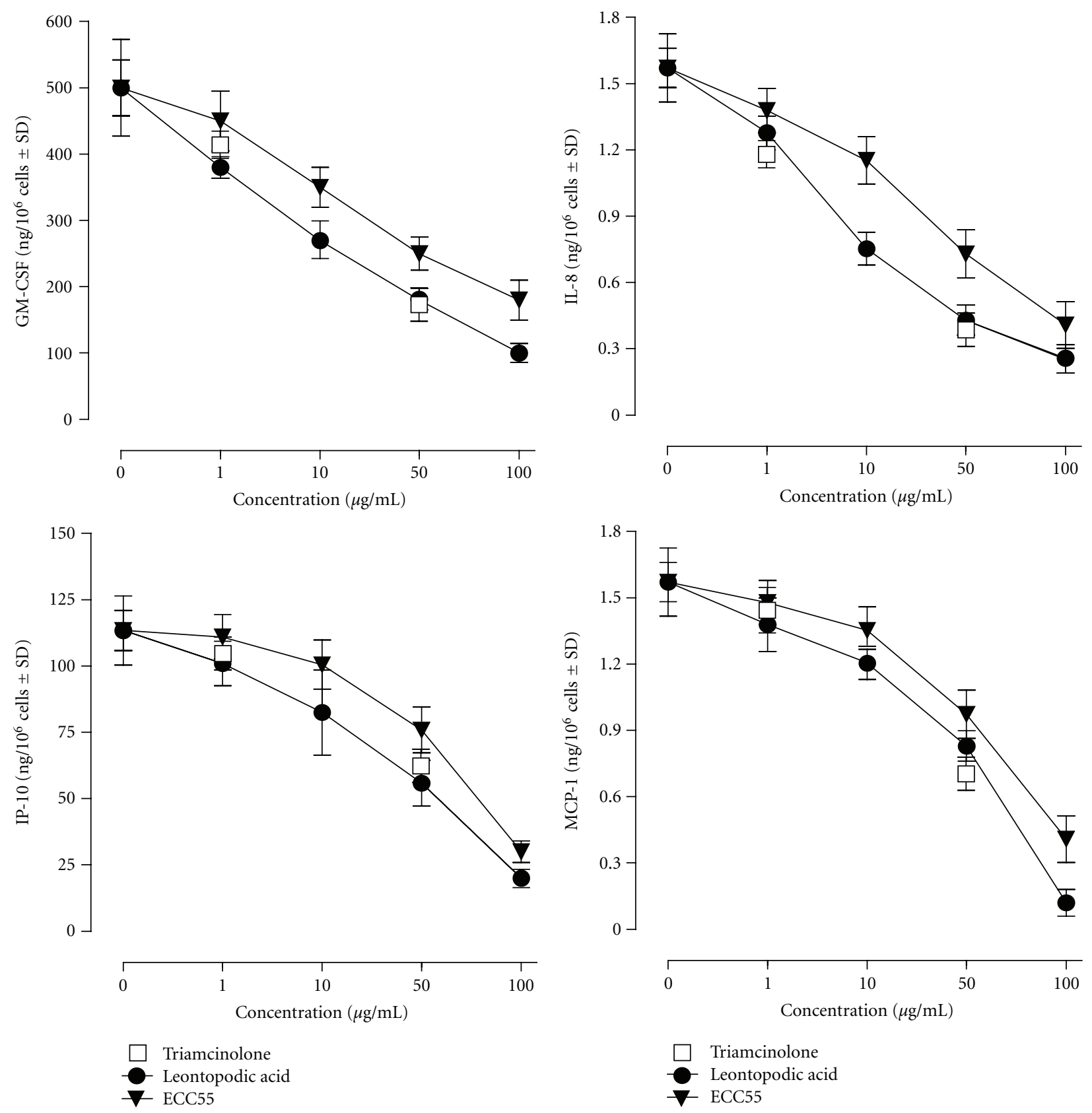

FIgURE 3: Dose-dependent effects of ECC55 and leontopodic acid on the chemokine and growth factor released from cultured human keratinocytes treated with proinflammatory combination of TNF $\alpha$ and IFN $\gamma$ (T/I). Concentrations (ng/10 ${ }^{6}$ cells) of granulocytemacrophage colony-stimulating factor (GM-CSF), interleukin 8 (IL-8), interferon gamma-produced protein of $10 \mathrm{kDa}$ (IP-10), and monocyte chemotactic protein-1 (MCP-1) were determined in the cellular supernatant at $24 \mathrm{~h}$ after keratinocyte challenge with T/I known to stimulate maximal inflammatory response. Keratinocytes were pretreated for $30 \mathrm{~min}$ with increasing concentrations $(\mu \mathrm{g} / \mathrm{mL})$ of either ECC55 or pure commercial leontopodic acid. The corticosteroid triamcinolone was used as a positive control for effective inhibition of cytokine/chemokine release at the two concentrations indicated. Error bars in all figures correspond to S.D. Background release of IL-8 was $0.29 \pm 0.04 \mathrm{ng} / 10^{6}$ cells, IP- 10 was $0.001 \pm 0.000 \mathrm{ng} / 10^{6}$ cells, GM-CSF was $0.07 \pm 0.01 \mathrm{ng} / 10^{6}$ cells, and MCP- 1 was $0.018 \pm 0.02 \mathrm{ng} / 10^{6}$ cells. Spontaneous production of IP-10 and MCP-1 was not changed in the presence of either ECC55 or pure commercial LA, whereas basal GM-CSF and IL-8 levels were decreased by ECC55 and LA dose dependently. 


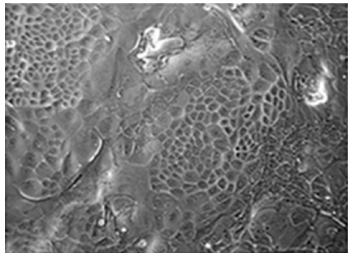

(a)
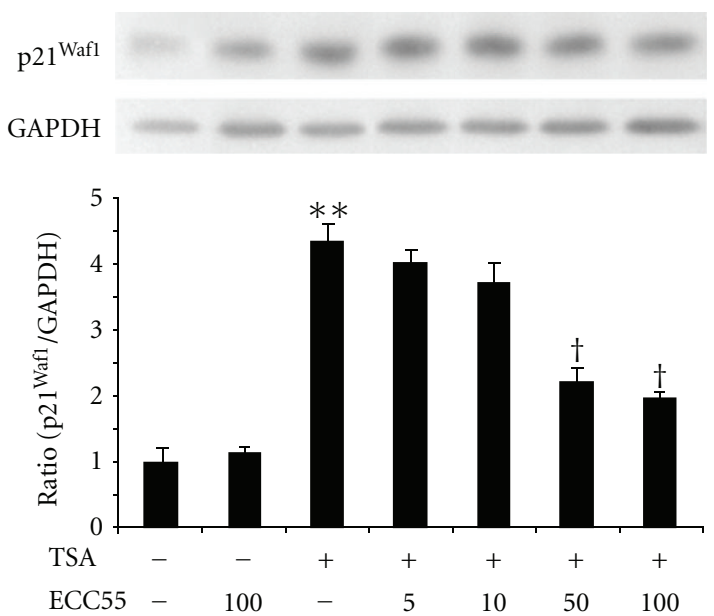

(e)
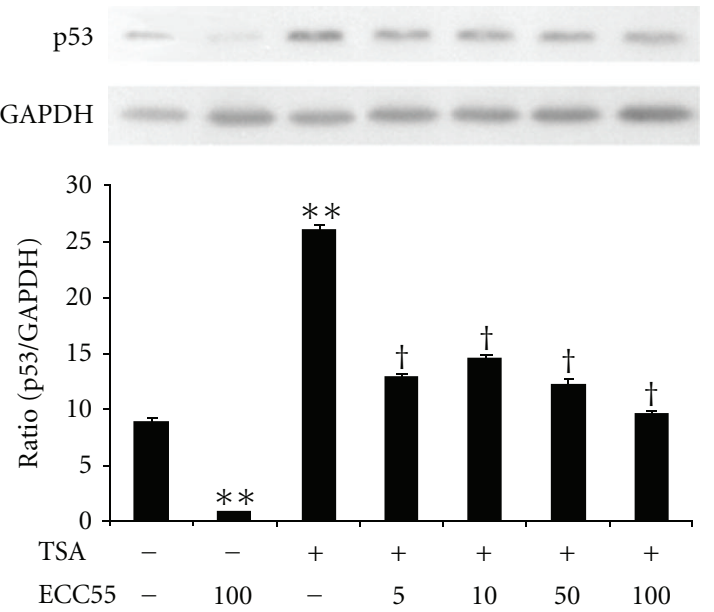

(g)

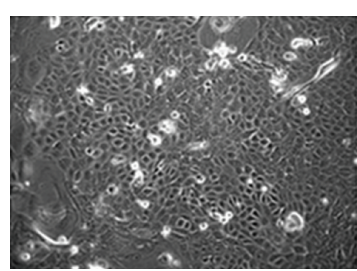

(c)

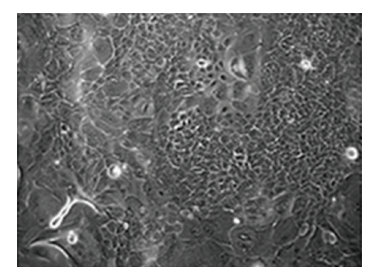

(d)
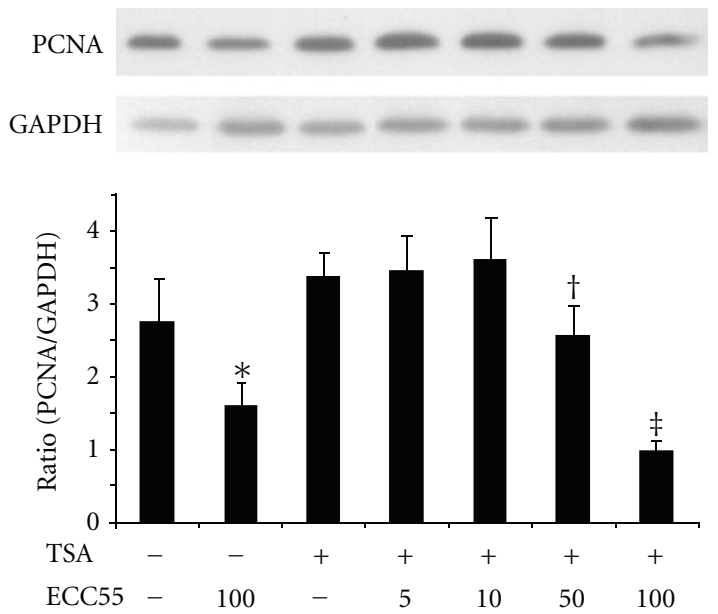

(f)
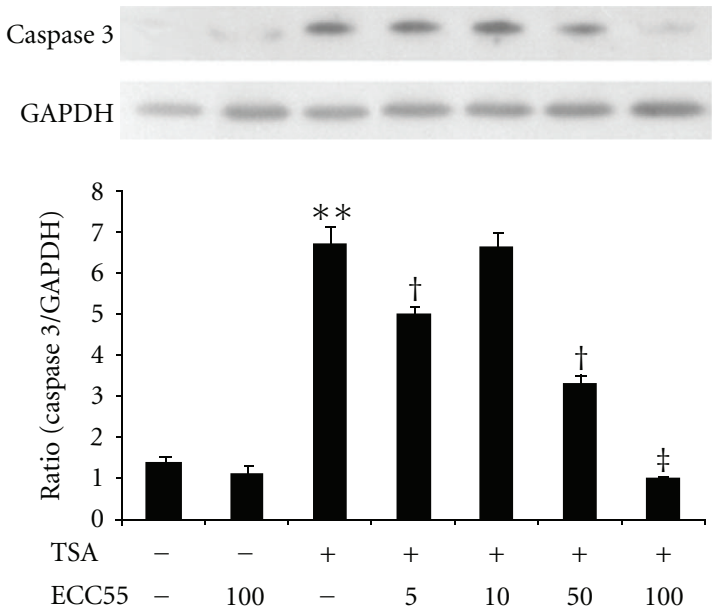

(h)

FIGURE 4: Effects of concentrated ethanol extract of Edelweiss callus cultures (ECC55) on Trichostatin A-induced cellular senescence and molecular markers of apoptosis, cell cycle, and proliferation. (a)-(d). Phase contrast microphotographs of cultivated human keratinocytes: untreated control (a), treated with Trichostatin A alone (b), treated with ECC55 alone (c), and treated with a combination of Trichostatin A and ECC55 (d). (e) Western blots and their densitometry showing p21 expression upon treatment with $100 \mu \mathrm{g} / \mathrm{mL}$ ECC55 alone, Trichostatin A (TSA) alone, or TSA combined with increasing concentrations of ECC55 (5-100 $\mu \mathrm{g} / \mathrm{mL})$. (f) The same for proliferation-connected nuclear antigen (PCNA). (g) The same for p53 and (h) for caspase 3. Error bars in all figures correspond to S.D. ${ }^{*} P<0.05$ and ${ }^{* *} P<0.01$ versus untreated control; ${ }^{\dagger} P<0.01$ and ${ }^{\ddagger} P<0.001$ versus TSA-treated keratinocytes.

to combat chronic colitis and attenuate sirtuin-connected inflammation in the intestinal epithelium [38-40]. In our hands, ECC55 showed remarkable sirtuin activating properties, which assumes its possible anti-inflammatory action through this molecular pathway.
3.6. Extract of Leontopodium alpinum Callus Cell Cultures ECC55 Selectively Inhibits LPS-Induced IL-6 and VCAM-1 Gene Expression and LDLox-Induced VCAM-1 Gene Expression in Cultured Human Endothelial Cells. Cellular adhesion molecules (CAMs), such as vascular cell adhesion molecule-1 


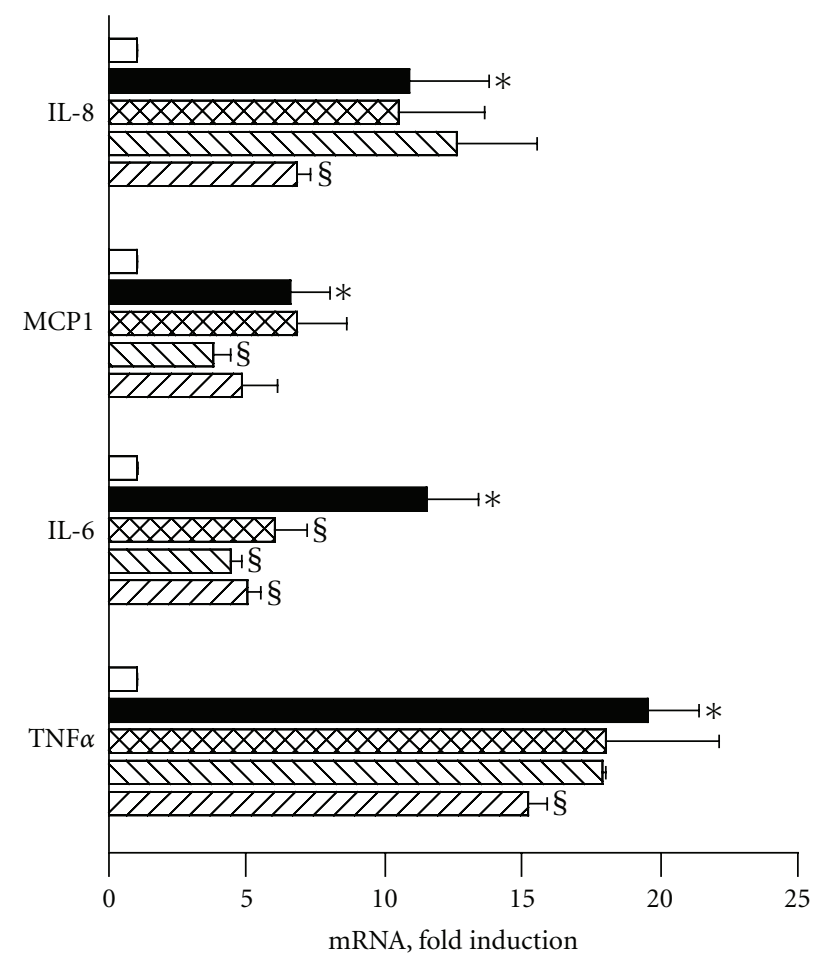

(a)

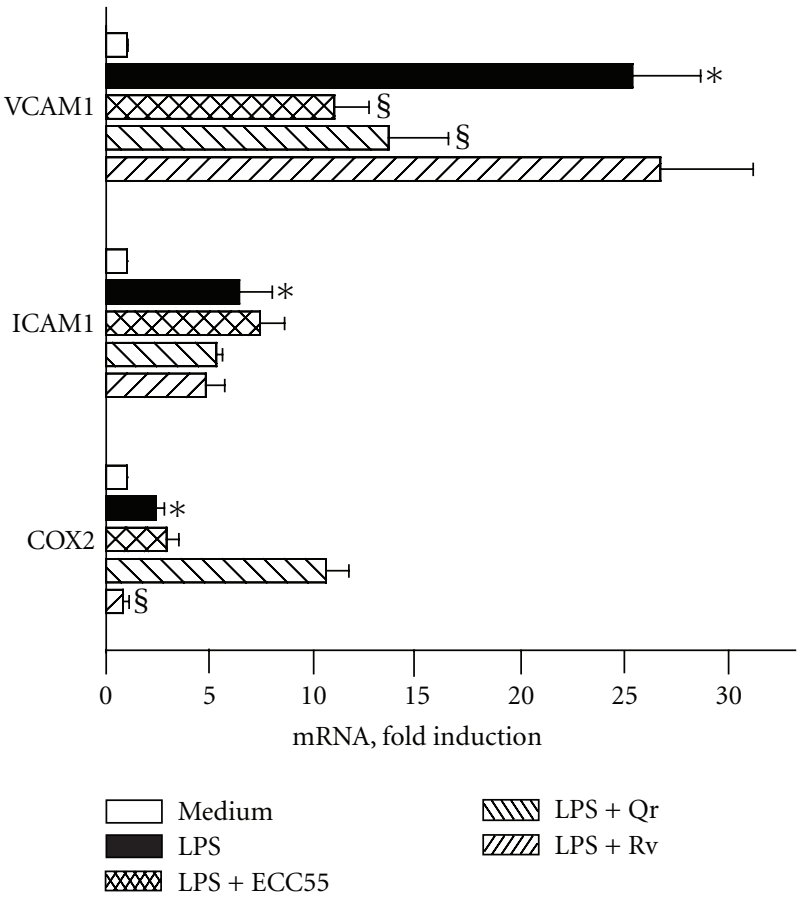

(b)

FIGURE 5: Effects of concentrated ethanol extract of Edelweiss callus cultures (ECC55) and reference anti-inflammatory plant polyphenols on inflammatory gene expression in human vascular endothelial cells (HUVECs) challenged with bacterial lipopolysaccharide (LPS). Abbreviations: $\mathrm{Qr}=$ quercetin, $25 \mu \mathrm{g} / \mathrm{mL}$; Rv = resveratrol, $25 \mu \mathrm{g} / \mathrm{mL}$; IL-8 = interleukin 8; MCP-1 = monocyte chemotactic protein-1; IL-6 = interleukin 6; TNF $\alpha=$ tumor necrosis factor alpha; VCAM1 = vascular cellular adhesion molecule-1; ICAM1 = intercellular adhesion molecule-1; COX2 = cyclooxygenase 2 . Error bars in all figures correspond to S.D. ${ }^{*} P<0.01$ versus untreated control; ${ }^{\S} P<0.01$ versus LPS-treated keratinocytes.

(VCAM-1), play a key role in initiating inflammatory responses of the vascular system [41]. Their expression in endothelial cells exposed to inflammatory stimuli causes accumulation of activated polymorphonuclear leukocytes and monocytes, leukocyte sticking, rolling, and penetration through the endothelial layer. As a result, vascular tissue damage by leukocyte-derived inflammatory mediators occurs followed by accelerated proliferation of vascular cells. In our experimental setting, we stimulated inflammatory responses in HUVEC cells by incubating them with classical triggers: bacterial lipopolysaccharide (LPS), a crucial proinflammatory trigger characteristic for bacterial infections, and human oxidized low-density lipoprotein (LDLox), a trigger of atherogenic inflammation. These two stimuli induced differential patterns of inflammatory cytokines, growth factors, adhesion molecules, and proinflammatory enzymes (Figures 5 and 6), as it has been reported previously [20]. While LPS significantly induced genes encoding chemokines for polymorphonuclear leukocytes (IL-8) and monocytes (MCP1), two early proinflammatory cytokines (TNF $\alpha$ and $I L$ 6), both CAMs expressed on endothelial cells (intercellular adhesion molecule (ICAM-1) and VCAM-1), as well as cyclooxygenase-2 (Figure 5), oxLDL induced IL-8, MCP-1, and VCAM-1 exclusively (Figure 6). Of particular interest, ECC55 selectively and remarkably reduced VCAM-1 gene expression in response to both triggers. None of the reference anti-inflammatory plant polyphenols studied ( $\mathrm{Qr}$ and $\mathrm{Rv}$ ) possessed such a selectivity, although all of them (ECC55, Qr, and $\mathrm{Rv}$ ) significantly inhibited LPS-induced $I L-6$ transcript (Figure 5). The molecular mechanism of VCAM-1 inhibition by Edelweiss extract deserves further profound investigation in order to provide a solid basis for its promising development as a targeted antivascular anti-inflammatory drug.

\section{Conclusions}

Concentrated Ethanol Extract of Leontopodium alpinum callus cell cultures containing phenolic fraction, $55 \%$ of which were leontopodic acids, possessed remarkable antiinflammatory properties at both transcriptional and translational levels in the cultured human skin keratinocytes and endothelial cells, thus confirming the ethnopharmacological use of the parental herb. The extract inhibited proinflammatory pathways dose dependently, and the effects were cell- and proinflammatory trigger-specific. Interestingly, the Leontopodium alpinum extract opposed the sirtuin inhibitor Trichostatin A, thus, possibly, activating sirtuin-associated intrinsic anti-inflammatory mechanisms. Biotechnologically produced Leontopodium alpinum cell cultures could be 


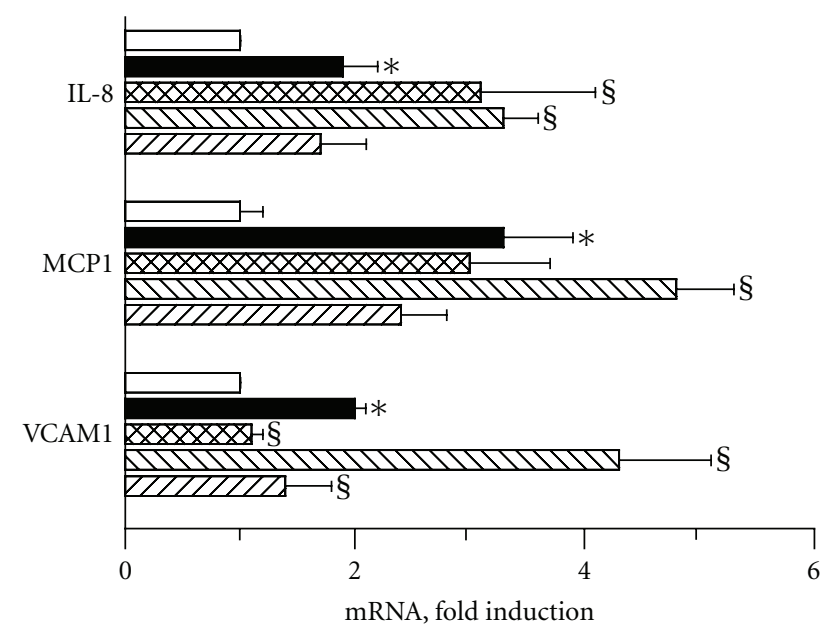

$\square$ Medium
LDLox
LDLox + ECC55

FIGURE 6: Effects of concentrated ethanol extract of Edelweiss callus cultures (ECC55) and reference anti-inflammatory plant polyphenols on inflammatory gene expression in human umbilical vein endothelial cells (HUVECs) challenged with oxidized human lowdensity lipoprotein (LDLox). Abbreviations are as in Figure 5. Error bars in all figures correspond to S.D. ${ }^{*} P<0.01$ versus untreated keratinocytes; ${ }^{\S} P<0.05$ versus LDLox-treated keratinocytes.

a valuable and biodiversity protective source of the natural anti-inflammatory substances feasible for chronic inflammatory skin diseases and bacterial and atherogenic inflammation.

\section{Acknowledgments}

The work was partly financed by the Grant from the Italian Ministry for Health (RC. IDI IRCCS-2009, 2.5). Generous help of CADEY S.p.a. (Milan, Italy) in covering the cost of the reagents is gratefully appreciated.

\section{References}

[1] J. H. Yoon and S. J. Baek, "Molecular targets of dietary polyphenols with anti-inflammatory properties," Yonsei Medical Journal, vol. 46, no. 5, pp. 585-596, 2005.

[2] M. J. Dobner, S. Sosa, S. Schwaiger et al., "Anti-inflammatory activity of Leontopodium alpinum and its constituents," Planta Medica, vol. 70, no. 6, pp. 502-508, 2004.

[3] U. Reisinger, S. Schwaiger, I. Zeller et al., "Leoligin, the major lignan from edelweiss, inhibits intimal hyperplasia of venous bypass grafts," Cardiovascular Research, vol. 82, no. 3, pp. 542549, 2009.

[4] S. Schwaiger, M. Adams, C. Seger, E. P. Ellmerer, R. Bauer, and H. Stuppner, "New constituents of Leontopodium alpinum and their in vitro leukotriene biosynthesis inhibitory activity," Planta Medica, vol. 70, no. 10, pp. 978-985, 2004.

[5] E. Speroni, S. Schwaiger, P. Egger et al., "In vivo efficacy of different extracts of edelweiss (Leontopodium alpinum Cass.) in animal models," Journal of Ethnopharmacology, vol. 105, no. 3, pp. 421-426, 2006.
[6] S. Costa, S. Schwaiger, R. Cervellati, H. Stuppner, E. Speroni, and M. C. Guerra, "In vitro evaluation of the chemoprotective action mechanisms of leontopodic acid against aflatoxin B1 and deoxynivalenol-induced cell damage," Journal of Applied Toxicology, vol. 29, no. 1, pp. 7-14, 2009.

[7] M. J. Dobner, S. Schwaiger, I. H. Jenewein, and H. Stuppner, "Antibacterial activity of Leontopodium alpinum (Edelweiss)," Journal of Ethnopharmacology, vol. 89, no. 2-3, pp. 301-303, 2003.

[8] S. Grabley and R. Thiericke, "Bioactive agents from natural sources: trends in discovery and application," Advances in Biochemical Engineering/Biotechnology, vol. 64, pp. 101-154, 1999.

[9] R. Chiej, "Edelweiss," in The Macdonald Encyclopoedia of Medicinal Plants, Macdonald Orbis, Hallatrow, UK, 1988.

[10] A. C. Dweck, "A review of edelweiss," SÖFT-Journal, vol. 130, pp. 65-68, 2004.

[11] S. Schwaiger, R. Cervellati, C. Seger et al., "Leontopodic acid-a novel highly substituted glucaric acid derivative from edelweiss (Leontopodium alpinum Cass.) and its antioxidative and DNA protecting properties," Tetrahedron, vol. 61, no. 19, pp. 4621-4630, 2005.

[12] S. Schwaiger, C. Seger, B. Wiesbauer et al., "Development of an HPLC-PAD-MS assay for the identification and quantification of major phenolic edelweiss (Leontopodium alpium Cass.) constituents," Phytochemical Analysis, vol. 17, no. 5, pp. 291298, 2006.

[13] L. G. Korkina and V. A. Kostyuk, "Biotechnologically produced secondary plant metabolites for cancer treatment and prevention," Current Pharmaceutical Biotechnology, vol. 12, pp. 265-275, 2011

[14] T. A. Thorpe, "History of plant tissue culture," Molecular Biotechnology, vol. 37, no. 2, pp. 169-180, 2007.

[15] L. G. Korkina, "Phenylpropanoids as naturally occurring antioxidants: from plant defense to human health," Cellular and Molecular Biology, vol. 53, no. 1, pp. 15-25, 2007.

[16] N. Crespi-Perellino, L. Garofano, E. Arlandini et al., "Identification of new diterpenoids from Euphorbia calyptrata cell cultures," Journal of Natural Products, vol. 59, no. 8, pp. 773$776,1996$.

[17] S. Pastore, F. Mascia, F. Mariotti, C. Dattilo, V. Mariani, and G. Girolomoni, "ERK1/2 regulates epidermal chemokine expression and skin inflammation," Journal of Immunology, vol. 174, no. 8, pp. 5047-5056, 2005.

[18] A. I. Potapovich, D. Lulli, P. Fidanza et al., "Plant polyphenols differentially modulate inflammatory responses of human keratinocytes by interfering with activation of transcription fators NF $\kappa \mathrm{B}$ and AhR and EGFR-ERK pathway," Toxicology and Applied Pharmacology, vol. 255, pp. 138-149, 2011.

[19] S. Pastore, F. Mascia, V. Mariani, and G. Girolomoni, "Keratinocytes in skin inflammation," Expert Reviews in Dermatology, vol. 1, pp. 279-291, 2006.

[20] V. A. Kostyuk, A. I. Potapovich, T. O. Suhan, C. De Luca, and L. G. Korkina, "Antioxidant and signal modulation properties of plant polyphenols in controlling vascular inflammation," European Journal of Pharmacology, vol. 658, no. 2-3, pp. 248$256,2011$.

[21] K. J. Livak and T. D. Schmittgen, "Analysis of relative gene expression data using real-time quantitative PCR and the 2$\Delta \Delta$ CT method," Methods, vol. 25, no. 4, pp. 402-408, 2001.

[22] H. Kojima, N. Nakatsubo, K. Kikuchi et al., "Detection and imaging of nitric oxide with novel fluorescent indicators, diaminofluoresceins," Analytical Chemistry, vol. 70, no. 13, pp. 2446-2453, 1998. 
[23] V. Kostyuk, A. Potapovich, T. Suhan et al., "Plant polyphenols against UV-C-induced cellular death," Planta Medica, vol. 74, no. 5, pp. 509-514, 2008.

[24] Y. Liu, F. Chan, H. Sun et al., "Resveratrol protects human keratinocytes HaCaT cells from UVA-induced oxidative stress damage by downregulating Keap1 expression," European Journal of Pharmacology, vol. 650, no. 1, pp. 130-137, 2011.

[25] P. Roy, E. Madan, N. Kalra et al., "Resveratrol enhances ultraviolet B-induced cell death through nuclear factor-kappa B pathway in human epidermoid carcinoma A431 cells," Biochemical and Biophysical Research Communications, vol. 384, pp. 215-220, 2009.

[26] L. G. Korkina, C. De Luca, V. A. Kostyuk, and S. Pastore, "Plant polyphenols and tumors: from mechanisms to therapies, prevention, and protection against toxicity of anti-cancer treatments," Current Medicinal Chemistry, vol. 16, no. 30, pp. 3943-3965, 2009.

[27] W. Liu and S. Wu, "Differential roles of nitric oxide synthases in regulation of ultraviolet B light-induced apoptosis," Nitric Oxide, vol. 23, no. 3, pp. 199-205, 2010.

[28] S. Pastore, D. Lulli, A. I. Potapovich et al., "Differential modulation of stress-inflammation responses by plant polyphenols in cultured normal human keratinocytes and immortalized HaCaT cells," Journal of Dermatological Science, vol. 63, no. 2, pp. 104-114, 2011.

[29] S. Wu, L. Wang, A. M. Jacoby, K. Jasinski, R. Kubant, and T. Malinski, "Ultraviolet B light-induced nitric oxide peroxynitrite imbalance in keratinocytes-implications for apoptosis and necrosis," Photochemistry and Photobiology, vol. 86, no. 2, pp. 389-396, 2010.

[30] R. Di Paola, E. Esposito, E. Mazzon et al., "3,5-Dicaffeoyl-4malonylquinic acid reduced oxidative stress and inflammation in a experimental model of inflammatory bowel disease," Free Radical Research, vol. 44, no. 1, pp. 74-89, 2010.

[31] M. Yonathan, K. Asres, A. Assefa, and F. Bucar, "In vivo antiinflammatory and anti-nociceptive activities of Cheilanthes farinosa," Journal of Ethnopharmacology, vol. 108, no. 3, pp. 462-470, 2006.

[32] J. Munro, N. I. Barr, H. Ireland, V. Morrison, and E. K. Parkinson, "Histone deacetylase inhibitors induce a senescence-like state in human cells by a p16-dependent mechanism that is independent of a mitotic clock," Experimental Cell Research, vol. 295, no. 2, pp. 525-538, 2004.

[33] S. Cordisco, R. Maurelli, S. Bondanza et al., "Bmi-1 reduction plays a key role in physiological and premature aging of primary human keratinocytes," Journal of Investigative Dermatology, vol. 130, no. 4, pp. 1048-1062, 2010.

[34] R. Rodriguez and M. Meuth, "Chk1 and p21 cooperate to prevent apoptosis during DNA replication fork stress," Molecular Biology of the Cell, vol. 17, no. 1, pp. 402-412, 2006.

[35] A. Balcerczyk and L. Pirola, "Therapeutic potential of activators and inhibitors of sirtuins," BioFactors, vol. 36, no. 5, pp. 383-393, 2010.

[36] S. Kyrylenko and A. Baniahmad, "Sirtuin family: a link to metabolic signaling and senescence," Current Medicinal Chemistry, vol. 17, no. 26, pp. 2921-2932, 2010.

[37] T. Vanhaecke, P. Papeleu, G. Elaut, and V. Rogiers, "Trichostatin A-like hydroxamate histone deacetylase inhibitors as therapeutic agents: toxicological point of view," Current Medicinal Chemistry, vol. 11, no. 12, pp. 1629-1643, 2004.

[38] S. Chung, H. Yao, S. Caito, J. W. Hwang, G. Arunachalam, and I. Rahman, "Regulation of SIRT1 in cellular functions: role of polyphenols," Archives of Biochemistry and Biophysics, vol. 501, no. 1, pp. 79-90, 2010.
[39] L. J. Hofseth, U. P. Singh, N. P. Singh, M. Nagarkatti, and P. S. Nagarkatti, "Taming the beast within: resveratrol suppresses colitis and prevents colon cancer," Aging, vol. 2, no. 4, pp. 183184, 2010.

[40] U. P. Singh, N. P. Singh, B. Singh et al., "Resveratrol (Trans3,5,4'-trihydroxystilbene) induces silent mating type information regulation-1 and down-regulates nuclear transcription factor- $\kappa \mathrm{B}$ activation to abrogate dextran sulfate sodiuminduced colitis," Journal of Pharmacology and Experimental Therapeutics, vol. 332, no. 3, pp. 829-839, 2010.

[41] A. Banning and R. Brigelius-Flohé, "NF- $\kappa \mathrm{B}$, Nrf2, and HO1 interplay in redox-regulated VCAM-1 expression," Antioxidants and Redox Signaling, vol. 7, no. 7-8, pp. 889-899, 2005. 


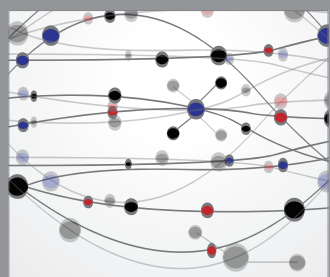

The Scientific World Journal
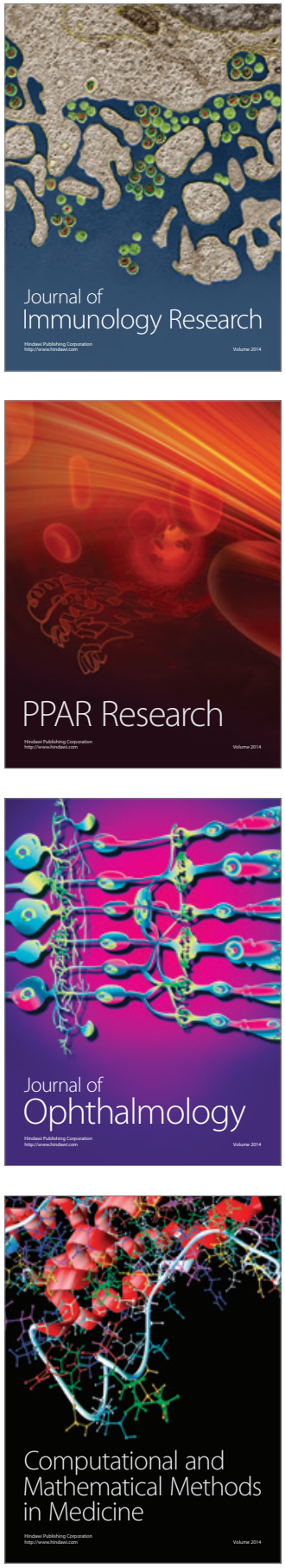

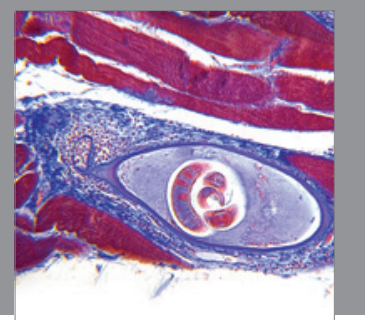

Gastroenterology

Research and Practice
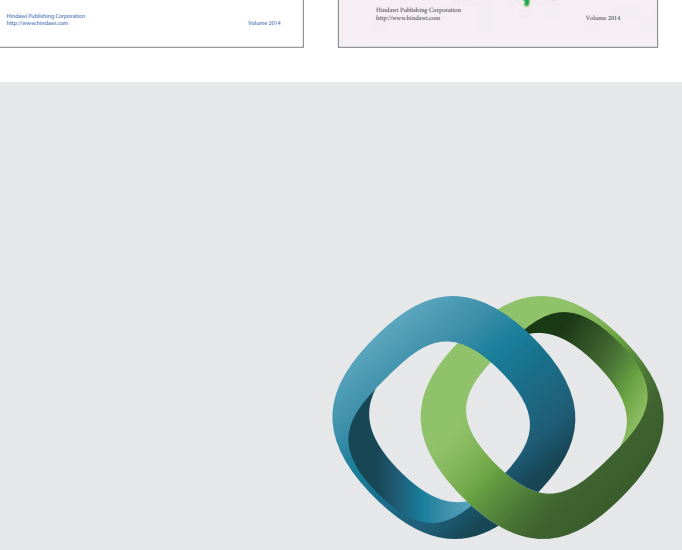

\section{Hindawi}

Submit your manuscripts at

http://www.hindawi.com
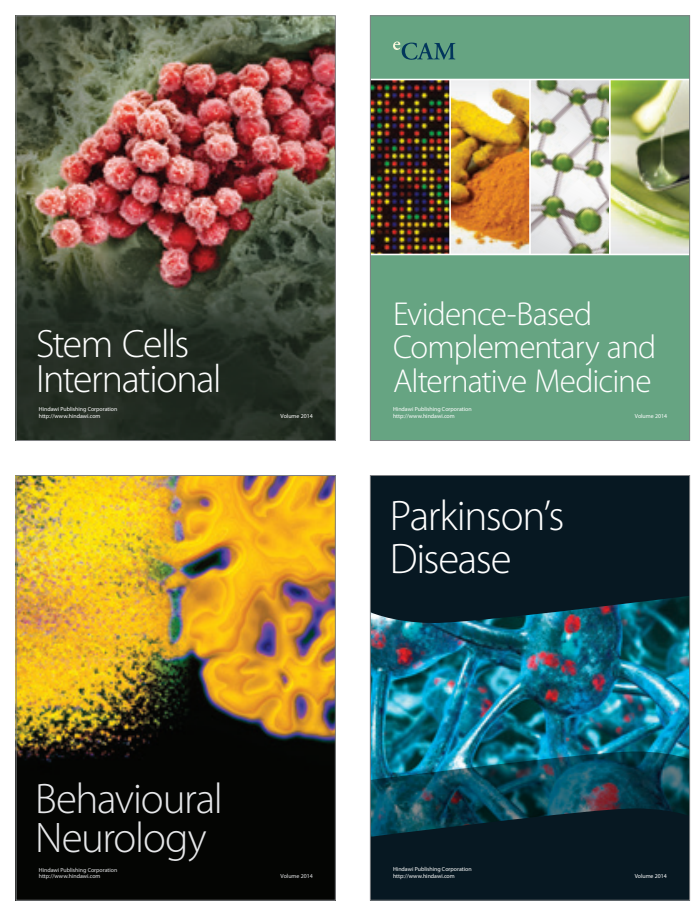

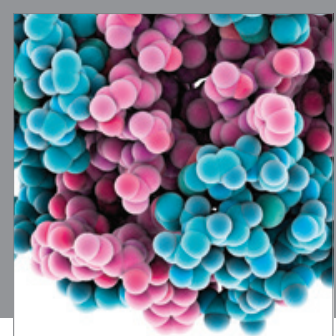

Journal of
Diabetes Research

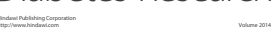

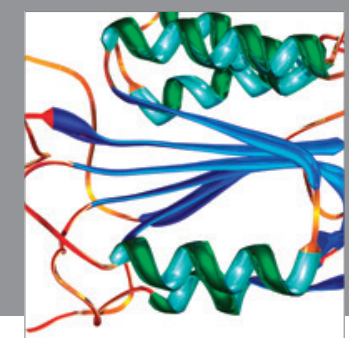

Disease Markers
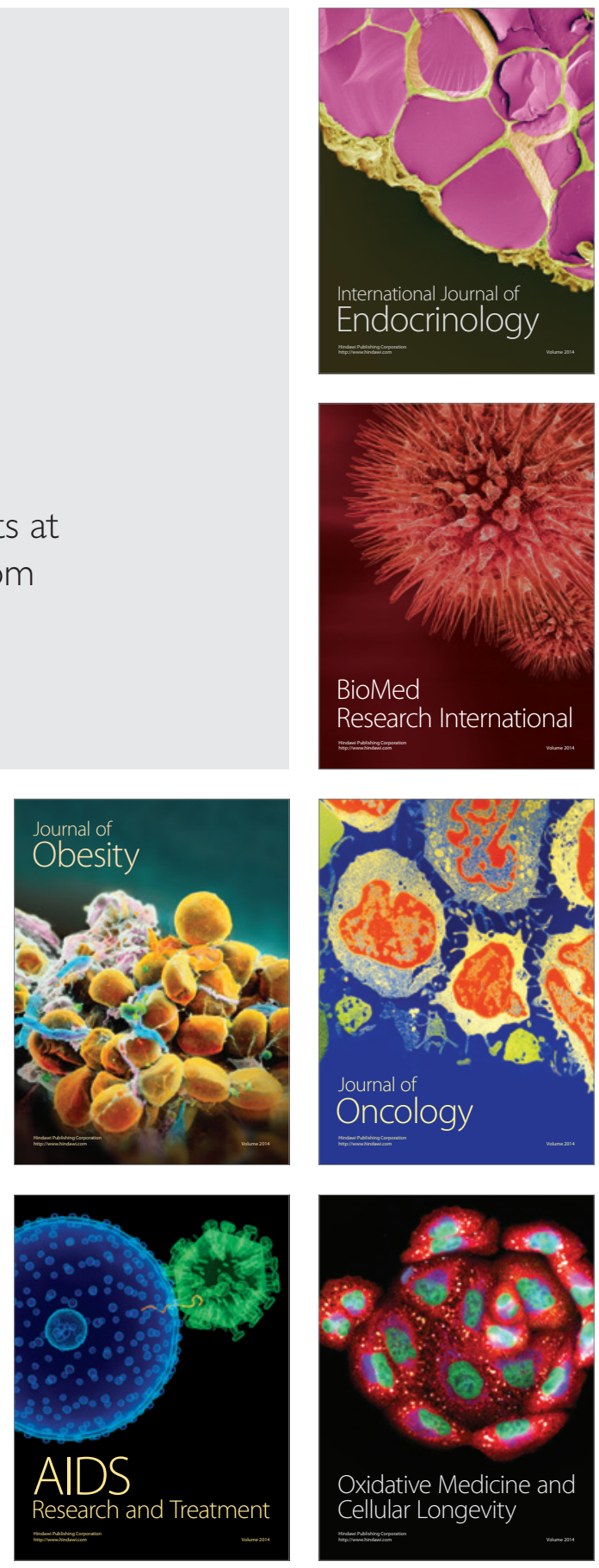